\title{
Psychosomatic Mechanisms Of Yoga
}

\section{Ananda Balayogi Bhavanani *}

Yoga is the original mind-body medicine that has enabled individuals to attain and maintain sukha sthanam, a dynamic sense of physical, mental and spiritual well being. Bhagavad-Gita defines Yoga as samatvam meaning thereby that Yoga is equanimity at all levels, a state wherein physical homeostasis and mental equanimity occur in a balanced and healthy harmony.

Yogamaharishi Dr Swami Gitananda Giri Guru Maharaj, the visionary founder of Ananda Ashram at the International Centre for Yoga Education and Research (ICYER) in Pondicherry and one of the foremost authorities on Yoga in the past century, has explained the concept of Yoga Chikitsa (Yoga as a therapy) in the following lucid manner.

"Yoga Chikitsa is virtually as old as Yoga itself, indeed, the 'return of mind that feels separated from the Universe in which it exists' represents the first Yoga therapy. Yoga Chikitsa could be termed as "man's first attempt at unitive understanding of mind-emotions-physical distress and is the oldest wholistic concept and therapy in the world."

To achieve this Yogic integration at all levels of our being, it is essential that we take into consideration the all encompassing multi dimensional aspects of Yoga that include the following: a healthy life nourishing diet, a healthy and natural environment, a wholistic lifestyle, adequate bodywork through Asanas, Mudras and Kriyas, invigorating breath work through the use of Pranayama and the production of a healthy thought process through the higher practices of Jnana Yoga and Raja Yoga.

\section{PSYCHOSOMATIC DISORDERS:}

The Nirvana Prakarana of the Laghu Yoga Vashishta, one of the ancient Yoga Texts describes in detail the origin and destruction of mental and bodily diseases. Sage Vashishta teaches Lord Rama that there are two major classifications of disease. Those that are caused by the mind are primary (adhija vyadhi, the psychosomatic, stress disorders) while those that afflict the body directly are secondary (anadhija vyadhi, infectious disease, accidents etc). The primary disease has two sub divisions. These are the samanya (ordinary physical diseases) and the Sara (the essential disorder of rebirth that may only be destroyed by atma jnana or knowledge of the Divine Self). Samanya diseases are the ones that affect us physically and may be destroyed by the correction of the mind-body disharmony. It is in these psychosomatic disorders that the actual practical application of Yoga practices as a mode of therapy can be very useful.

From the Yogic viewpoint of disease it can be seen that psychosomatic, stress related disorders appear to progress through four distinct phases. These can be understood as follows:

1. Psychic Phase: This phase is marked by mild but persistent psychological and behavioural symptoms of stress like irritability, disturbed sleep and other minor symptoms. This phase can be correlated with vijnanamaya and manomaya koshas. Yoga as a mind body therapy is very effective in this phase.

2. Psychosomatic Phase: If the stress continues there is an increase in symptoms, along with the appearance of generalized physiological symptoms such as occasional hypertension and tremors. This phase can be correlated with manomaya and pranamaya koshas. Yoga as a mind body therapy is very effective in this phase.

3. Somatic Phase: This phase is marked by disturbed function of organs, particularly the target, or involved organ. At this stage one begins to identify the diseased state. This phase can be correlated with pranamaya and annamaya koshas. Yoga as a therapy is less effective in this phase and may need to be used in conjunction with other methods of treatment.

\footnotetext{
* Yogacharya Dr. Ananda Balayogi Bhavanani, MBBS, ADY, DPC, DSM, PGDFH, PGDY, FIAY, MD (Alt.Med)

Deputy Director, CYTER, MGMCRI, SBVU and Chairman ICYER at Ananda Ashram, Pondicherry.

Email: yoga@mgmcri.ac.in and yognat@gmail.com
} 


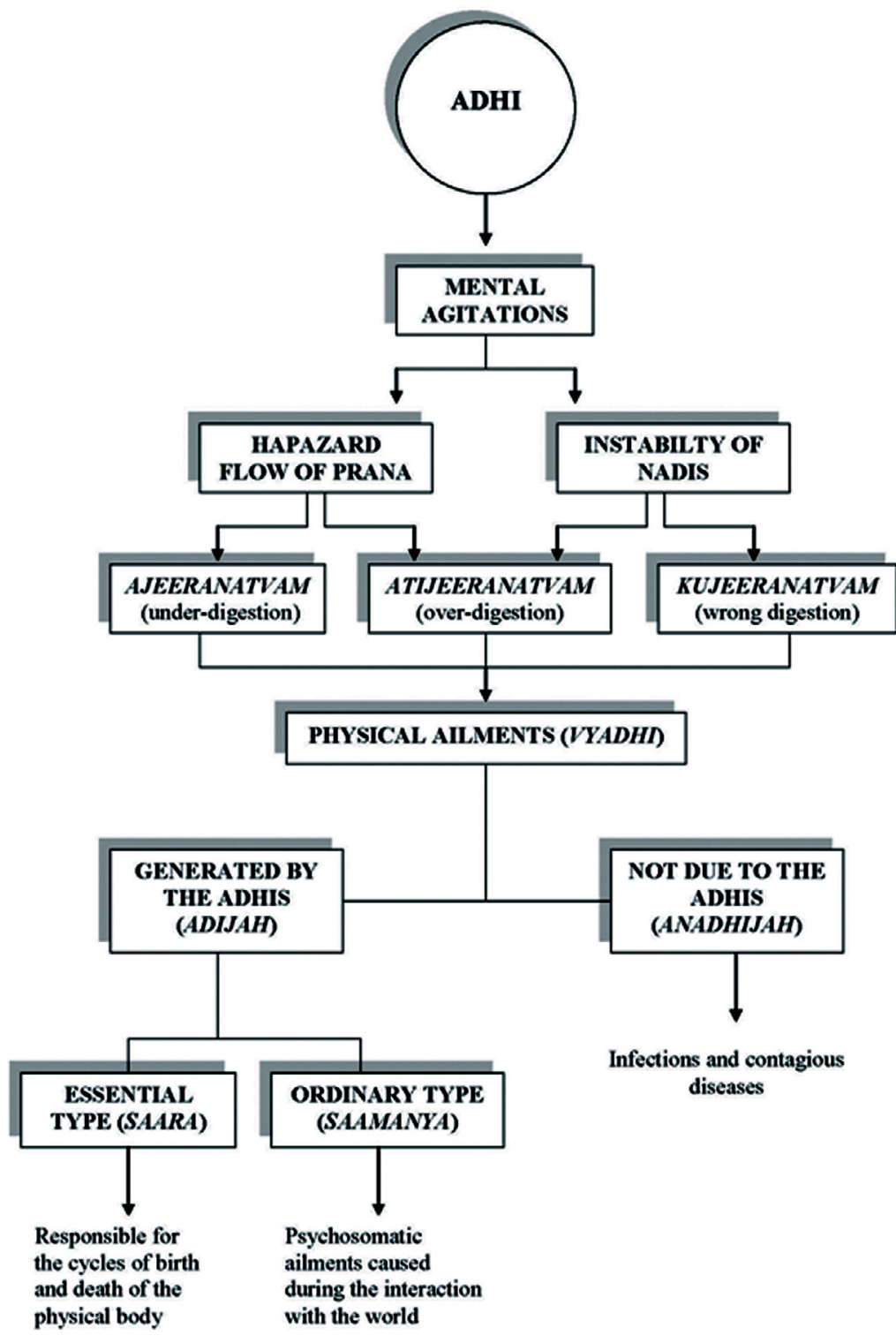

The Yogic Concept of Origin of Disease

4. Organic Phase: This phase is marked by full manifestation of the diseased state, with pathological changes such as an ulcerated stomach or chronic hypertension, becoming manifest in their totality with their resultant complications. This phase can be correlated with the annamaya kosha as the disease has become fixed in the physical body. Yoga as a therapy has a palliative and 'quality of life improving' effect in this phase. It also has positive emotional and psychological effects even in terminal and end of life situations.

\section{POtentialities:}

Extensive research on Yoga being done all over the world has shown promise with regard to various disorders and diseases that seem to be amiable to Yoga therapy (www.iayt.org, www.icyer.com, www.svyasa.org). These include psychosomatic, stress disorders such as bronchial asthma, diabetes mellitus, hypertension, irritable bowel syndrome, gastro intestinal ulcer diseases, atherosclerosis, seizure disorder and headache. It also includes physical disorders such as heart disease, lung disease, and mental retardation. Psychiatric disorders such as anxiety disorders, obsessive-compulsive disorder, depression and substance abuse can also be managed along with other therapies. Musculoskeletal disorders such as lumbago, spondylosis, sciatica and carpel tunnel syndrome can be tackled effectively with Yoga practices that offer a lot of hope in metabolic disorders such as thyroid and other endocrine disorders, immune disorders, obesity and the modern metabolic syndrome. 
It is well established that stress weakens our immune system. Scientific research in recent times has showed that the physiological, psychological and biochemical effects of Yoga are of an anti-stress nature. Mechanisms postulated included the restoration of autonomic balance as well as an improvement in restorative, regenerative and rehabilitative capacities of the individual. A healthy inner sense of wellbeing produced by a life of Yoga percolates down through the different levels of our existence from the higher to the lower producing health and wellbeing of a holistic nature.

Streeter et al (2012) recently proposed a theory to explain the benefits of Yoga practices in diverse, frequently comorbid medical conditions based on the concept that Yoga practices reduce allostatic load in stress response systems such that optimal homeostasis is restored.

They hypothesized that stress induces an:

1. Imbalance of the ANS with decreased parasympathetic and increased sympathetic activity,

2. Under activity of the gamma amino-butyric acid (GABA) system, the primary inhibitory neurotransmitter system, and

3. Increased allostatic load.

They further hypothesized that Yoga-based practices

1. Correct underactivity of the parasympathetic nervous system and GABA systems in part through stimulation of the vagus nerves, the main peripheral pathway of the parasympathetic nervous system, and

2. Reduce allostatic load.

According to the theory proposed by Streeter and colleagues, the decreased parasympathetic nervous system and GABAergic activity that underlies stress-related disorders can be corrected by Yoga practices resulting in amelioration of disease symptoms. HRV testing has a great role to play in our understanding intrinsic mechanisms behind such potential effects of Yoga.

Innes et al had earlier (2005) also postulated two interconnected pathways (given below) by which Yoga reduces the risk of cardiovascular diseases through mechanisms of parasympathetic activation coupled with decreased reactivity of sympathoadrenal system and HPA axis.

\section{PSYCHOSOMATIC MeChanisms Of Yoga:}

Yoga understands the influence of the mind on the body as well as that of the body on the mind. This is the principle of adhi-vyadhi elucidated in the Yoga Vasishta more than 5000 years ago! It is interesting that modern medicine has only realised this connection in the last hundred years whereas Yogic of India were teaching and practising it for thousands of years. No wonder Yoga may be considered as the original mind-body medicine.

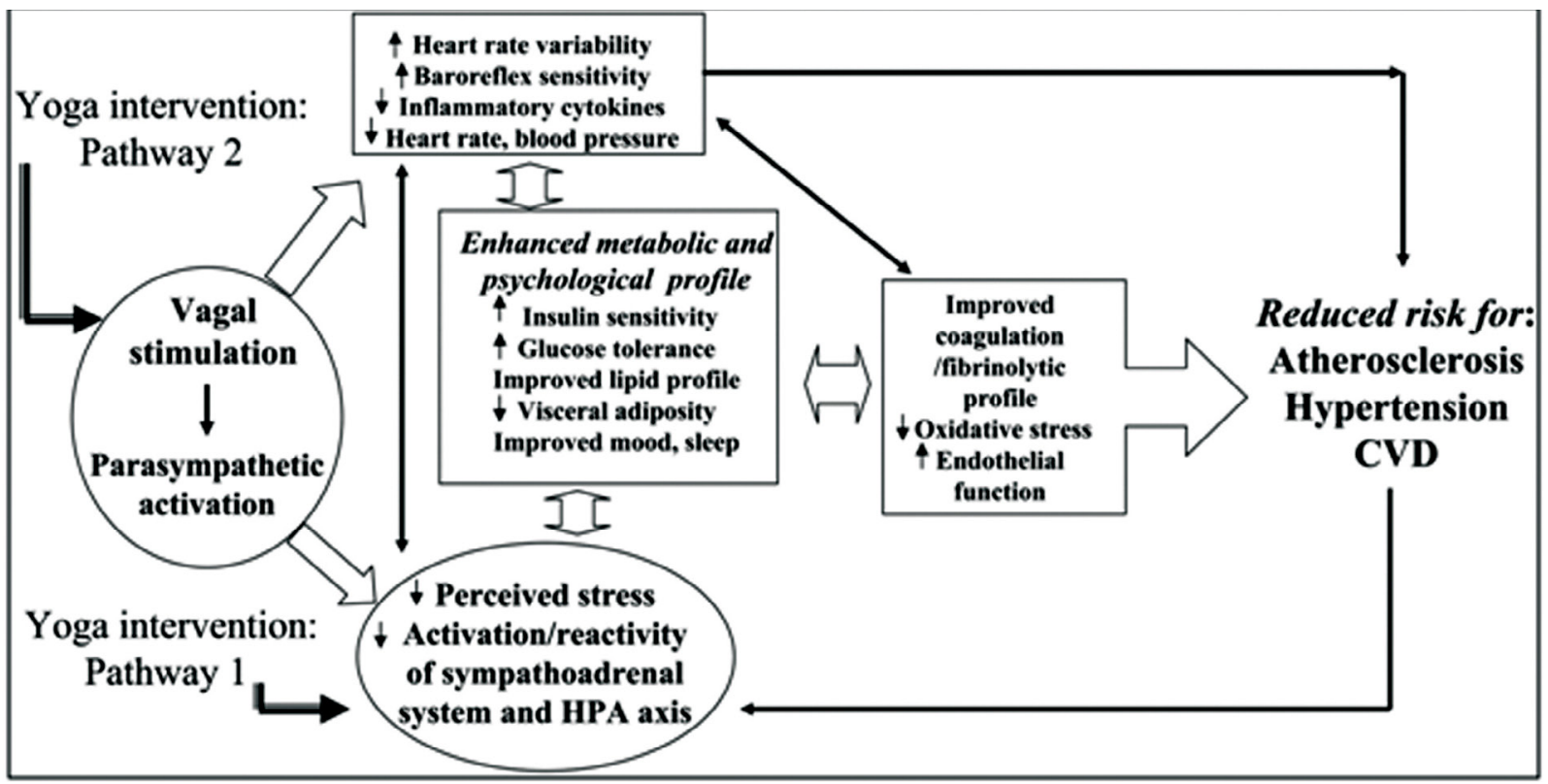

We are what we think, yet we also start to think that which we do. Yogic concepts and techniques enable the development of right attitudes towards life and enable us to correct the numerous internal and external imbalances we suffer due to our wrong lifestyle/ genetic potential. Yoga enables us to take responsibility for our own health and happiness and as Swami Gitananda Giri would say, "If you want to be healthy do healthy things, if you want to be happy 
do happy things".

The following are just a few of the mechanisms through which Yoga can be said to work as an integrated mind-body medicine:

1. Cleanses the accumulated toxins through various shuddi kriyas and generates a sense of relaxed lightness through jathis and vyayama type activities. Free flow in all bodily passages prevents the many infections that may occur when pathogens stagnate therein.

2. Adoption of a Yogic lifestyle with proper nourishing diet, creates positive antioxidant enhancement thus neutralizing free radicals while enabling a rejuvenative storehouse of nutrients packed with life energy to work on anabolic, reparative and healing processes .

3. Steadies the entire body through different physical postures held in a steady and comfortable manner without strain. Physical balance and a sense of ease with oneself enhance mental / emotional balance and enable all physiological processes to occur in a healthy manner.

4. Improves control over autonomic respiratory mechanisms though breathing patterns that generate energy and enhance emotional stability. The mind and emotions are related to our breathing pattern and rate and hence the slowing down of the breathing process influences autonomic functioning, metabolic processes as well as emotional responses.

5. Integrates body movements with the breath thus creating psychosomatic harmony. In Yoga the physical body is related to annamaya kosha (our anatomical existence) and the mind to manomaya kosha (our psychological existence). As the pranayama kosha (our physiological existence sustained by the energy of the breath) lies in between them, the breath is the key to psychosomatic harmony.

6. Focuses the mind positively on activities being done, thus enhancing energy flow and resultant healthy circulation to the different body parts and internal organs. Where the mind goes, there the prana flows!

7. Creates a calm internal environment through contemplative practices that in turn enable normalization of homeostatic mechanisms. Yoga is all about balance or samatvam at all levels of being. Mental balance produces physical balance and vice versa too.

8. Relaxes the body-emotion-mind complex through physical and mental techniques that enhance our pain threshold and coping ability in responding to external and internal stressors. This enhances the quality of life as seen in so many terminal cases where other therapies are not able to offer any solace.

9. Enhances self confidence and internal healing capacities through the cultivation of right attitudes towards life and moral-ethical living through yama-niyama and various Yogic psychological principles. Faith, self confidence and inner strength are most essential if at all we wish for healing, repair, rejuvenation and re-invigoration.

10. Yoga works towards restoration of normalcy in all systems of the human body with special emphasis on the psycho-neuro-immuno-endocrine axis. In addition to its preventive and restorative capabilities, Yoga also aims at promoting positive health that will help us to tide over health challenges that occur during our lifetime. This concept of positive health is one of Yoga's unique contributions to modern healthcare as Yoga has both a preventive as well as promotive role in the healthcare of our masses. It is also inexpensive and can be used in tandem with other systems of medicine in an integrated manner to benefit patients.

\section{NEED For COORDination:}

The need of the modern age is to have an integrated approach towards therapy and to utilize Yoga therapy in coordination and collaboration with other systems of medicine such as Allopathy, Ayurveda, Siddha and Naturopathy. Physiotherapy and Chiropractic practices may be used with the Yoga if needed. Advice on diet and lifestyle is very important irrespective of the mode of therapy that is employed for a particular patient.

\section{A WORD OF CAUTION:}

A word of caution is also required. Though Yoga and Yoga therapy are very useful in bringing about a state of total health it is not a miracle cure for all problems. It needs a lot of discrimination on the part of both the therapist as well as the patient. It may not be useful in emergency conditions and there is a strong need to consult a qualified medical doctor where in doubt. Each patient is different and so the therapy has to be molded to suit the individual needs rather than relying on a specific therapy plan for patients suffering the same medical condition.

A very true problem is that there is a different approach of the different schools of Yoga to the same condition. It is better to follow any one system that one is conversant with, rather than trying to mix systems in a "Yogic Cocktail'. One must also be vigilant as there is a strong presence of numerous quacks pretending to be Yoga therapists and this leads to a bad name for Yoga therapy as well as Yoga in general. 


\section{CONCLUSION:}

The dedicated practice of Yoga as a way of life is no doubt a panacea for problems related to psychosomatic, stress related physical, emotional and mental disorders and helps us regain our birthright of health and happiness. It is only when we are healthy and happy that we can fulfill our destiny. With the adoption of a proper attitude and lifestyle through the Yogic way of life, we can rise above our own circumstances and our life can blossom as a time of variety, creativity, and fulfillment.

Yoga helps us regain the ease we had lost through dis-ease (as implied by sthira sukham asanam-PYS). It also produces mental equanimity (samatvam yoga uchyate-BG) where the opposites cease to affect (tato dwandwa anabhigatha-PYS). This enables us to move from a state of illness and disease to one of health and well being that ultimate allows us to move from the lower animal nature to the higher human nature and finally the highest Divine Nature that is our birthright.

\section{References And Recommended ReAding:}

1.Ananda Balayogi Bhavanani. A Primer of Yoga Theory. Dhivyananda Creations, Iyyanar Nagar, Pondicherry. 2008. www.rishiculture.org

2.Back issues of International Journal of Yoga Therapy. Journal of the International Association of Yoga Therapists, USA. www.iayt.org

3.Back issues of Yoga Life, Monthly Journal of ICYER at Ananda Ashram, Pondicherry. www.icyer.com

4.Back issues of Yoga Mimamsa. Journal of Kaivalyadhama, Lonavla, Maharashtra, USA. www.kdham.com

5. Innes KE, Bourguignon C, Taylor AG. Risk indices associated with the insulin resistance syndrome, cardiovascular disease, and possible protection with yoga: a systematic review. J Am Board Fam Pract 2005;18: 491-519.

6. Srimad Bhagavad Gita by Swami Swarupananda. Advaita Ashrama, Kolkata. 2007

7.Streeter CC, Gerbarg PL, Saper RB, Ciraulo DA, Brown RP. Effects of yoga on the autonomic nervous system, gamma-aminobutyric-acid, and allostasis in epilepsy, depression, and post-traumatic stress disorder. Med Hypotheses 2012; 78:571-9.

8.The Supreme Yoga: Yoga Vashista. Swami Venkatesananda. Motilal Banarsidass Publishers Pvt Ltd.Delhi. 2007

9.Ananda Balayogi Bhavanani. Yoga for health and healing. Dhivyananda Creations, Iyyanar Nagar, Pondicherry. 2008.

10.Anantharaman TR. Ancient Yoga and Modern Science. Mushiram Manoharlal Publishers Pvt Ltd, New Delhi. 1996

11. Ananda Balayogi Bhavanani. Yoga Chikitsa-Application of Yoga as a Therapy Dhivyananda Creations, Iyyanar Nagar, Pondicherry. 2013. www.rishiculture.org

12. Yoga: Step-by-Step. A 52 lesson Correspondence Course by Yogamaharishi Dr. Swami Gitananda Giri. Ananda Ashram at ICYER, Pondicherry. www.icyer.com

13. The Forceful Yoga (being the translation of the Hathayoga Pradipika, Gheranda Samhita and Siva Samhita). Translated into English by Pancham Sinh, Rai Bahadur Srisa Chandra Vasu and Romanized and edited by Dr GP Bhatt. Mothilal Banarsidas Publishers Private Limited, Delhi. 2004.

14. Yoga the Science of Holistic Living. Vivekananda Kendra Patrika. Vol. 17- 2. 1988.

15. Taimni IK. The Science of Yoga. The Theosophical Publishing House, Chennai.1961

16. Meena Ramanathan. Thiruvalluvar on Yogic Concepts. Aarogya Yogalayam, Venkateswara Nagar, Saram, Pondicherry-13.2007

17. Swami Satyananda Saraswathi. Four Chapters on Freedom. Bihar School of Yoga, Munger, India. 1999

18. Nagarathna R and Nagendra HR. Integrated approach of Yoga therapy for positive health. Swami Vivekananda Yoga Prakashana, Bangalore, India. 2001.

19. Healthy mind, healthy body. Sri Ramakrishna Math, Chennai, India.1997.

20. Feuerstein Georg. The Shambala Guide to Yoga. Shambala Publications Inc, Boston, Massachusetts, and USA.1996. 